\title{
ÁGUA: QUAL A CONCEPÇÃO E ATITUDES DOS ESTUDANTES DOS CURSOS TÉCNICOS DO INSTITUTO FEDERAL CATARINENSE CAMPUS CONCÓRDIA?
}

\author{
Guilherme Pieri Pereira ${ }^{1}$ \\ Hewerton Enes De Oliveira ${ }^{2}$ \\ Alessandra Farias Millezi ${ }^{3}$
}

Resumo: $O$ atendimento à demanda por água de boa qualidade é um dos principais desafios mundiais na atualidade do homem e de toda a biota terrestre. Propostas educativas visando o esclarecimento sobre o uso racional dos recursos hídricos são necessárias. Para elaboração dessas propostas é indispensável obter subsídios acerca do conhecimento e de atitudes dos estudantes em relação à água e seu uso. Tendo em vista a problemática, buscou-se com esse trabalho conhecer a concepção dos estudantes dos cursos Técnicos sobre conceitos relativos à água e também em relação à utilização desse recurso tão importante em nossas vidas.

Palavras-chave: Educação Ambiental; Mananciais; Aquíferos.

${ }^{1}$ IF Catarinense, Câmpus Concórdia, SC, E-mail: amillezi@yahoo.com.br

2 IF Catarinense, Câmpus Concórdia, SC, E-mail: hewerton.oliveira@concordia.ifc.edu.br

${ }^{3}$ IF Catarinense, Câmpus Concórdia, SC, E-mail: alessandra.millezi@ifc-concordia.edu.br 


\section{Introdução}

A água é um recurso indispensável para a existência da vida. Foi na água que a vida floresceu, e seria difícil imaginar a existência de qualquer forma de vida na ausência deste recurso vital.

Nosso planeta está inundado d'água; um volume de aproximadamente 1,4 bilhão de $\mathrm{km}^{3}$, cobre cerca de $71 \%$ da superfície da Terra. A grande oferta fez da água a substância ideal para ser empregada como solvente universal na limpeza e transporte de praticamente todos os resíduos gerados pelo homem. Ao redor de todo o mundo, as cidades foram se estabelecendo e crescendo próximas a grandes cursos d'água (GRASSI, 2001, p. 31).

De acordo com Victorino (2007, p.18), nos dias de hoje, os grandes problemas ligados à água não acontecem por causa da natureza, mas sim da má utilização com desperdício e imprevidência. A aparente abundância de água na natureza talvez justifique, em parte, a negligência histórica dos seres humanos nas suas relações com os recursos hídricos. Sabemos que não existe tanta água potável disponível como a paisagem nos faz ver. O que na realidade temos como água potável é apenas $0,03 \%$ do total de água do planeta. Essa insignificante quantia deveria receber todos os cuidados possíveis, no entanto, não é isso o que vemos em quase todos os continentes, os principais aquíferos estão sendo exauridos com uma rapidez maior do que sua taxa natural de recarga.

Nessa perspectiva, o desperdício e a má utilização, além da crescente contaminação dos lençóis freáticos, são problemas causados pelo desconhecimento da maneira correta do uso dos mananciais. O controle da contaminação do solo é um dever que todos nós temos para com as águas subterrâneas, e é nesse contexto que entra a questão ambiental e consequentemente a Educação Ambiental que trabalhamos com os nossos estudantes.

A questão ambiental relativa à água transformou-se e um dos mais sérios desafios que a sociedade tem de enfrentar em curto prazo. A consciência ambiental não surge no vazio, ela envolve uma realidade caótica deste recurso natural como: poluição, escassez, degradação, exploração desordenada, desigualdades sociais, interferência do sistema econômico e político e a ocupação desordenada do espaço ambiental.

A Educação Ambiental (EA) surge no Brasil muito antes da sua institucionalização no governo federal. Temos a existência de um persistente movimento conservacionista até o início dos anos 1970, quando ocorre a emergência de um ambientalismo que se une às lutas pelas liberdades democráticas (BRASIL, 2007, p. 13). A Educação Ambiental depende do ambiente escolar, dos alunos e do professor, é notável a falta de conhecimento e esclarecimento de conceitos básicos por parte dos estudantes e o pior é que também há essa carência entre os docentes. Isso reflete diretamente nas atitudes de cada um em relação ao uso da água. 
A EA vem atualmente sendo abordada como uma alternativa para a construção de valores e conhecimentos nos primeiros níveis da educação escolar. A reflexão sobre as práticas sociais, em um contexto marcado pela degradação permanente do meio ambiente e do seu ecossistema, envolve uma necessária articulação com a produção de sentidos no tocante ao desenvolvimento do sentimento de pertencimento a este ambiente e também com relação à percepção das questões ambientais (PARENTE, 2010, p.137). Para Caporal e Costabeber (2000, p.27), a EA vem sendo incorporada como uma prática inovadora em diferentes âmbitos. Neste sentido, destaca-se tanto sua "internalização como objeto de políticas públicas de educação e de meio ambiente em âmbito nacional"), quanto sua incorporação num âmbito mais capilarizado, como mediação educativa, por um amplo conjunto de práticas de desenvolvimento social (ARENDT, 1989, p.189; PARENTE, 2014, p.5).

Tendo em vista a problemática apresentada, buscou-se com esse trabalho conhecer a concepção dos estudantes dos cursos Técnicos em Agropecuária e Alimentos sobre conceitos relativos à água e também em relação à utilização desse recurso tão importante em nossas vidas.

\section{Material e métodos}

\section{Local de condução do experimento}

O presente estudo foi realizado no Instituto Federal Catarinense, Campus Concórdia, Santa Catarina, Brasil

\section{Procedimentos Metodológicos}

Foi aplicado questionário com perguntas estruturadas e dirigidas à obtenção de respostas objetivas, sendo que os alunos escolheram a alternativa que consideraram correta, de acordo com seus conhecimentos e atitudes sobre o tema água.

Foi entrevistado um total de 165 estudantes do primeiro ano dos cursos Técnico em Agropecuária e Técnico em Alimentos do Instituto Federal Catarinense, Campus Concórdia.

\section{Tabulação de dados}

Os dados foram tabulados e gráficos foram gerados utilizando o programa Microsoft Office Excel 2007. 


\section{Resultados e discussão}

Nas questões abordadas, procurou-se formulá-las de maneira a obter respostas condizentes com a realidade do conhecimento dos estudantes e também de suas atitudes.

Os resultados demonstraram que os estudantes carecem de conhecimentos básicos sobre o tema água, apesar da maioria responder corretamente às questões conceituais, houve alta porcentagem de estudantes que escolheram a resposta errada, isso demonstra a falta de conhecimentos básicos de questões ambientais relativas ao tema água.

$\mathrm{Na}$ questão sobre mananciais hídricos (Figura 1), 39,05\% responderam que mananciais são reservas hídricas poluídas, sendo que mananciais são fontes de onde se retira a água com condições sanitárias adequadas e vazão suficiente para atender a demanda, e de acordo com Tucci (1997, p. 14), se dividem entre subterrâneos e superficiais.

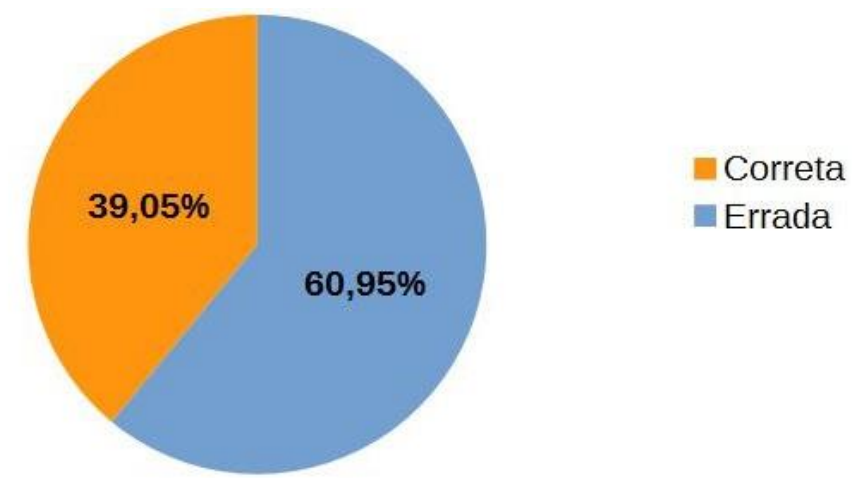

Figura 1: Percentagem quanto à afirmação de que mananciais são reservas hídricas ou fontes poluídas que não podem ser utilizadas para o abastecimento público de água.

A segunda questão abordou se os estudantes sabiam explicar corretamente o que é um lençol freático, 49,57\% responderam que sim, porém $50,43 \%$ não sabem ou não têm certeza se saber responder (Figura 2). Verificase também que parte significativa dos estudantes não possuem assimilado o conhecimento sobre lençóis freáticos.

A chuva que cai nos continentes escoa para regiões mais baixas, formando rios, lagos e pântanos, até encontrar o oceano. Parte da água que atinge os continentes infiltra-se no solo e preenche os espaços entre as rochas, formando os lençóis freáticos e aquíferos, e possuem renovação muito lenta. No lençol freático a superfície da zona de saturação do solo ou das rochas porosas acumulam água subterrânea (MEC, 2009, p. 12). 


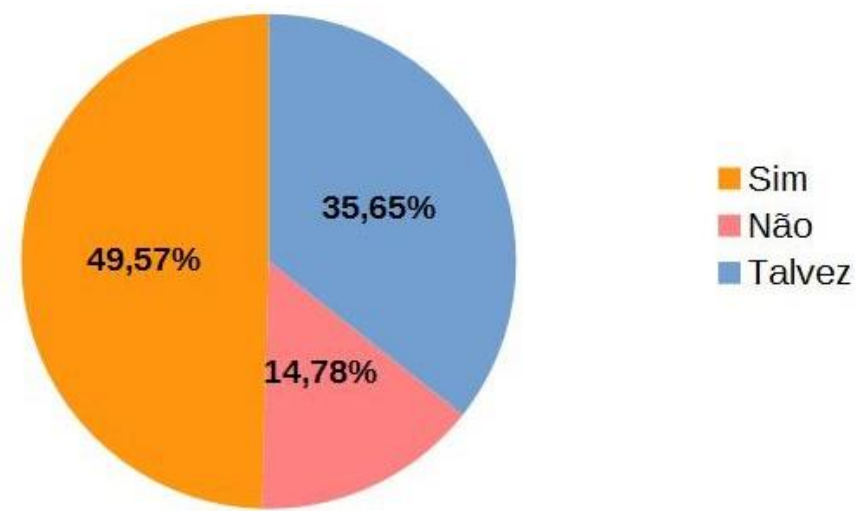

Figura 2: Percentagem de respostas à questão: "Você sabe explicar corretamente o que é o lençol freático?"

A maioria dos estudantes respondeu corretamente que a afirmação "O deslocamento de cargas por vias fluviais não oferece riscos associados à poluição das águas com lixo e óleo" está errada. Entretanto, 23,58\% consideraram a afirmação correta e 15,45\% responderam não saber (Figura 3).

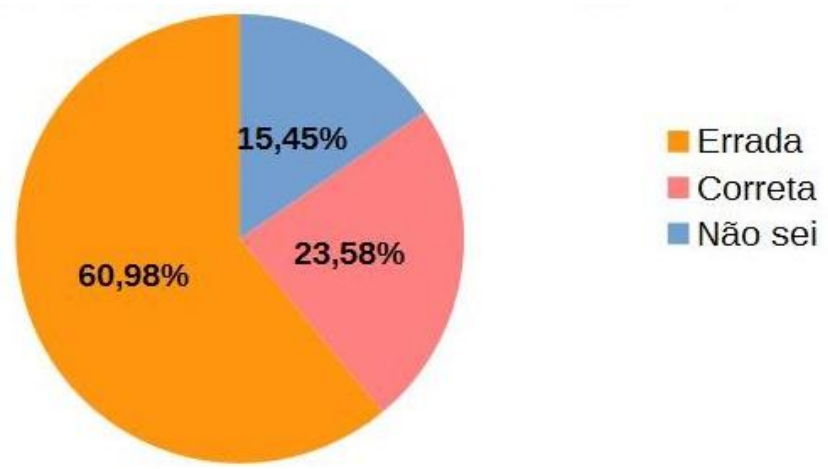

Figura 3: Percentagem de respostas à afirmativa: "O deslocamento de cargas por vias fluviais não oferece riscos associados à poluição das águas com lixo e óleo".

Tucci $(2008$, p.97) sugere que o planejamento e a gestão racional da água são condições essenciais para que áreas urbanizadas se desenvolvam sustentavelmente. De acordo com o autor, o abastecimento de água tratada, o tratamento de esgotos, a recuperação e a preservação de áreas de várzea, as obras de infraestrutura de drenagem urbana, bem como a coleta e a correta destinação dos resíduos sólidos são ações que devem ser planejadas e geridas de forma a proteger a saúde humana e conservar os recursos naturais.

Em relação às atitudes ou ações, verificou-se que $10,62 \%$ dos estudantes responderam que em suas casas existe uma forma de aproveitar a água da chuva, a maioria não faz esse reuso da água e uma pequena Revbea, São Paulo, V. 11, № 4: 328-335, 2016. 
percentagem de $1,77 \%$ afirmou não saber da existência de uma forma de aproveitar a água proveniente das chuvas (Figura 4).

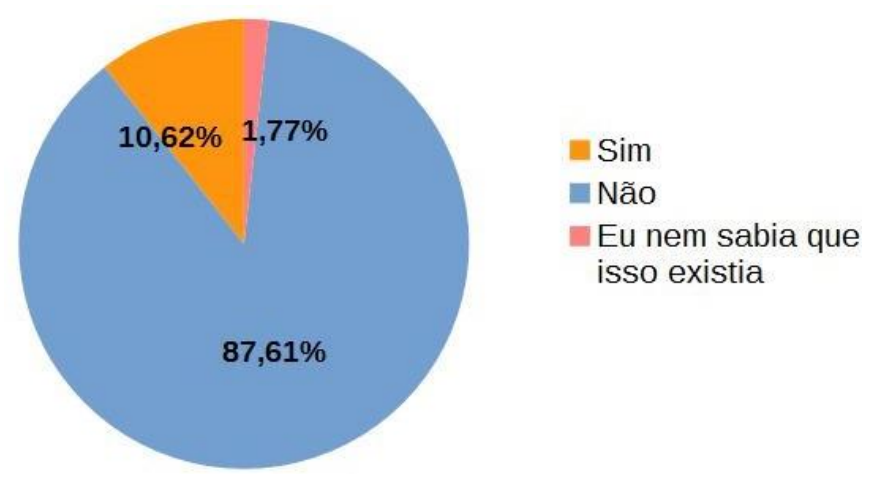

Figura 4: Percentagem de respostas à questão: "Na sua casa há um aproveitamento de águas da chuva?".

Os melhores horários para regar plantas são de manhã e no fim da tarde (depois das 15h). Regar em horários com maior insolação, como ao meio dia faz com que boa parte da água evapore, pois é um horário muito quente. À noite a planta absorve pouca água, e suas folhas demoram muito a secar (APRENDENDO A REGAR AS PLANTAS, 2015).

Utilizar um regador ao invés de uma mangueira evita o desperdício de água e facilita regar na quantidade necessária para a planta, evitando exageros e excessos. Contudo, verificou-se que a maioria dos estudantes $64,04 \%$ não tem o cuidado com o período do dia e não usa um regador (Figura 5).

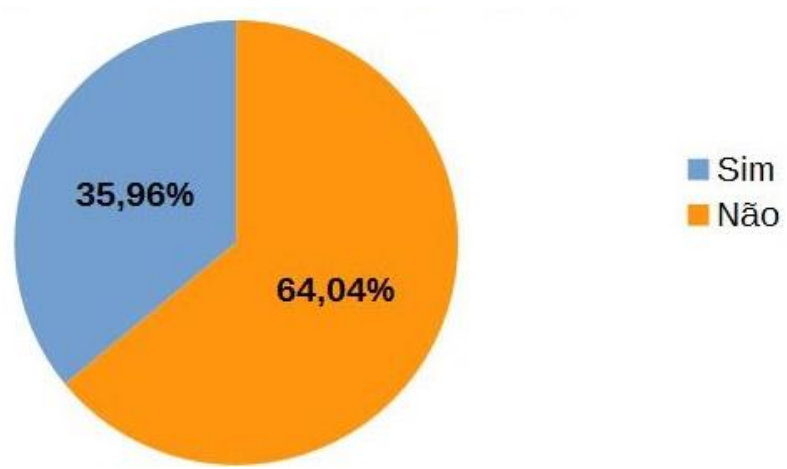

Figura 5: Percentagem de respostas à questão: "Para regar plantas, você tem o cuidado com o período do dia e usa um regador ao invés de usar uma mangueira?". 
Alguns estudantes infelizmente possuem visões de exploração desenfreada em relação aos recursos naturais, esquecendo-se que muitas vezes os recursos são fundamentais à vida.

Uma hipótese é que os assuntos relativos ao tema água estejam sendo trabalhados de maneira muito superficial. As situações de ensino e aprendizagem baseadas na discussão do tema social e ambiental água podem facilitar o desenvolvimento de atitudes responsáveis. A discussão dos problemas permite que 0 aluno compreenda os recursos naturais, as tecnologias, bem como suas consequências na sociedade.

De acordo com Pereira et al. (2014, p.46), ações práticas são importantes para proporcionar maior clareza dos conceitos, sendo que nessa perspectiva, segundo Vygotsky, a linguagem é adquirida e desenvolvida quando a interação entre indivíduos com níveis de formação diferenciados se encontram em grupos heterogêneos de trabalho; e atividades nesse sentido são importantes para criar um espaço de construção coletiva e colaborativa entre os estudantes. Millezi et al. (2013, p. 45) relata em seu trabalho, o desenvolvimento de atividade didática com estudantes de classe multisseriada sobre "A água", em que foi realizado desenho do corpo humano relacionandose o sistema circulatório aos cursos dos rios, contextualizando a importância da preservação dos recursos hídricos assim como é necessário cuidar do corpo humano.

O conhecimento e a prática em Educação Ambiental compõem uma situação complexa, pois envolvem várias áreas com visões diferenciadas. Os professores carregam diferentes concepções e valores que são revelados em sua prática pedagógica (TORRALBO, 2009, p.11).

\section{Considerações finais}

Verificou-se com esta experiência que os estudantes precisam assimilar melhor conceitos relativos ao tema água na perspectiva ambiental. A importância de abordar o tema água no ensino é entendida como um recurso para realizar aproximações entre os conceitos químicos e biológicos e as situações do cotidiano do aluno. $O$ assunto água pode ser problematizado pelos professores a fim de investigar e interpretar situações importantes para os estudantes de maneira que os conceitos possam auxiliar no entendimento e resolução de problemas, como por exemplo na questão abordada nessa pesquisa sobre o horário recomendado para se regar plantas.

Deve-se também buscar propiciar a formação de um estudante crítico e responsável com questão ambiental em seu contexto global.

Agradecimento: Ao apoio financeiro do IFC - Campus Concórdia. 


\section{Referências}

ARENDT, H A. A condição humana. Rio de Janeiro: Forense, 234 p. 1989.

APRENDENDO A REGAR AS PLANTAS. Disponível em: http://www.cultivando.com.br/termos tecnicas regando da melhor forma.html.

Acesso em: 27 de janeiro de 2015.

BRASIL. CADERNOS SECAD 1. Educação Ambiental: aprendizes de sustentabilidade. Brasília, DF; MEC, 103 p, 2007.

CAPORAL, F.R., COSTABEBER, J.A. Agroecologia e Desenvolvimento Rural Sustentável: Perspectivas para uma Nova Extensão Rural. Agroecologia e Desenvolvimento Rural Sustentável. V. 1, P. 16- 37, 2000.

FONTES, A.; SILVA, I.R. Uma nova forma de aprender ciências: a educação em Ciência/Tecnologia/Sociedade (CTS). Coleção Guias Práticos. Editora: Edições, 2004.

GRASSI, T.M. As águas do planeta Terra. Cadernos Temáticos de Química Nova na Escola. Edição especial, p. 31-40, maio de 2001.

PEREIRA, G.P.; SILVA, J.R.P.L.; MOREIRA, V.S.; GUBERT, A.L.; OLIVEIRA, H.E.; MILLEZI, A.F. Eixo lixo: concepção ambiental de estudantes dos cursos técnicos do Instituto Federal Catarinense - Câmpus Concórdia. Revista Extensão Tecnológica: Revista de Extensão do Instituto Federal Catarinense, Ano 1, n. 2, p. $43-46,2014$.

MILLEZI, A.F. FÁVERO, D.G.; FRADE, E.G. Reconstrução de percursos em Educação Ambiental por intermédio do projeto "O Jogo de Não Jogar". Revista da ANPG Ciência, Tecnologia e Políticas Educacionais, v.1, n.1, p.40-49, 2013.

MINISTÉRIO DA EDUCAÇÃO. PROCESSO FORMADOR EM EDUCAÇÃO AMBIENTAL A DISTÂNCIA: MÓDULO 3: MUDANÇAS AMBIENTAIS GLOBAIS. Brasília: Secretaria de Educação Continuada, Alfabetização e Diversidade, 175 p. 2009.

PARENTE, C.M.D. A construção dos tempos escolares. Educação em Revista, v. 26, 135-156, 2010.

PARENTE C.M.D. Escolas Multisseriadas: a experiência internacional e reflexões para o caso brasileiro Ensaio: aval. pol. públ. Educ., Rio de Janeiro, v.22, n. 82, p. 57-88, jan./mar. 2014.

TORRALBO, D. O tema água no ensino: a visão de pesquisadores e de professores de Química. Dissertação de Mestrado, Universidade de São Paulo, 2009.

TUCCI, Carlos E.M. Água no meio urbano: Livro da água doce - cap 14, Instituto de pesquisa hidráulica. UFGRS - Porto Alegre- RS: 1997.

TUCCI, C. E. M. Águas urbanas. Estudos Avançados, São Paulo, v. 22, n. 63, p. 97-112, 2008.

VICTORINO, C.J.A. Planeta água morrendo de sede: uma visão analítica na metodologia do uso e abuso dos recursos hídricos. Porto Alegre: EDIPUCRS, 2007. 231 p.

revista brasileira educação ambiental 